\title{
periferio
}

\section{AUDIOVISUALIDADES E PRODUÇÃO SOCIAL DAS MASCULINIDADES: GÊNEROS-CORPOS-SEXUALIDADES ENCENADAS NOS COTIDIANOS \\ DAS SALAS DE AULA}

\author{
Leonardo Nolasco-Silva ${ }^{1}$ \\ Universidade do Estado do Rio de Janeiro - UERJ \\ Bruno Rossato ${ }^{2}$ \\ Secretaria de Educação do Rio de Janeiro - SME/RJ
}

\section{Resumo}

Neste texto pensamos a potência das audiovisualidades como dispositivos pedagógicos atuantes no dentrofora ${ }^{3}$ das salas de aula. Partimos da compreensão que a formação se dá em redes de significação e subjetividades, não redutíveis à experiência escolar/acadêmica. Como recorte, discutiremos as apropriações que os praticantes das nossas salas de aula fazem dos personagens-heróis de desenhos animados e de uma série de TV, concebendo o audiovisual como tecnologia social participante da produção simbólica dos corpos e dos comportamentos. Estas narrativas - que são disparadoras de subjetivação - servirão de linha para os nossos pespontos teóricos sobre a construção social das masculinidades, tema que atravessa os cotidianos da educação formal ainda de maneira muito tímida. De que modo as encenações do masculino presentes nessas produções atravessam os estudantes e potencializam discursos sobre as masculinidades? Que pistas o consumo destes audiovisuais oferecem para pensarmos juntos as (des)construções de gênero nos cotidianos da escola e da universidade? Como esses disparadores e as conversas tecidas a partir deles nos ajudam a pensar o currículo?

Palavras-chave: masculinidades; audiovisualidades; cotidiano escolar

\footnotetext{
1 Pós-Doutor em Educação. Professor Adjunto da Faculdade de Educação - UERJ. leonolascosilva@gmail.com

2 Mestre em Educação - UERJ. Professor de Educação Infantil - Secretaria Municipal de Educação do Rio de Janeiro. rossatbruno@yahoo.com.br

$3 \mathrm{Na}$ tendência de pesquisa em Educação conhecida como Pesquisas nos/dos/com os Cotidianos, a qual nos filiamos, grafamos algumas palavras juntas para afirmar a complexidade dos conhecimentos e modos de conhecer tecidos com as práticas, a qual não pode ser expressa por meio das dicotomias inventadas com a narrativa científica que se tornou hegemônica na modernidade histórica.
} 


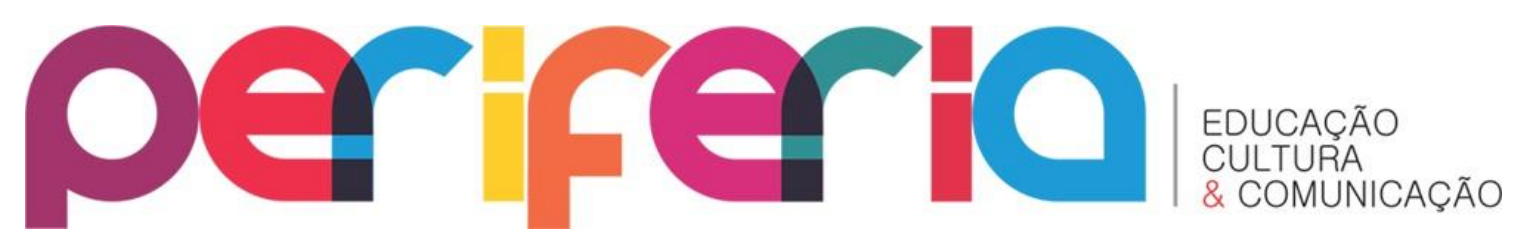

\title{
AUDIOVISUALITIES AND SOCIAL PRODUCTION OF MASCULINITIES: GENDERS-BODIES-SEXUALITIES STAGED IN THE DAILY LIFE OF CLASSROOMS
}

\begin{abstract}
In this text we think of the power of audiovisualities as pedagogical devices within/outside the classroom. We start from the understanding that the formation takes place in networks of signification and subjectivities, not reducible to the scholastic / academic experience. As a focus, we will discuss the appropriations that the practitioners of our classrooms make of the cartoon and TV series characters-heroes designing the audiovisual as a social technology that participates in the symbolic production of bodies and behaviors. These narratives - which are triggers of subjectivation - will serve as a line for our theoretical points of view on the social construction of masculinities, a theme that crosses the everyday of formal education in a very timid way. In what way do the male plays present in these productions cross students and potentialize discourses on masculinities? What clues to the use of these audiovisualities allow us to think together the (dis) constructions of gender in the daily life of the school and the university? How do these triggers and the conversations woven from them help us think about the curriculum?
\end{abstract}

Keywords: masculinities; audiovisualities; school's everyday 


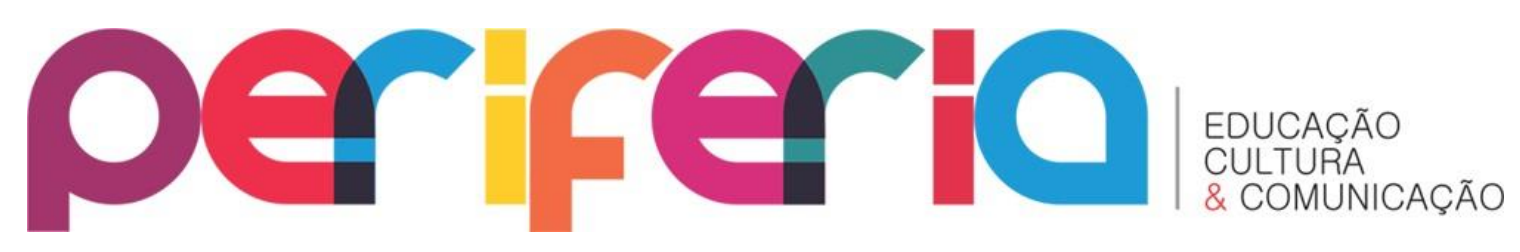

MASCULINIDADES NA REDE: (DES) FAZENDO GÊNERO NO CIBERESPAÇO

"Um dia vivi a ilusão de que ser homem bastaria”. Gilberto Gil, Super-Homem (a canção).

Escrevemos enquanto o mundo lá fora (um fora que também é o ao dentro da gente) repercute a cultura do estupro e, por conseguinte, inspeciona os pilares instáveis da construção social das masculinidades, indicando arbitrariedades e riscos. Escrevemos em meio às certezas vulneráveis acumuladas no decorrer de processos incessantes de socialização uma socialização aparentemente favorável aos seres humanos que possuem a marca do masculino como sexo biológico - igualmente construído e arbitrário (PRECIADO, 2014) - mas que também é peso de responsabilidades impostas e expectativas colecionadas por todos aqueles que querem o bem dos homens (bem casados, bem ativos sexualmente, bem viris, bem acima de qualquer suspeita, homens de bem). Mas, ao dizermos isto, não estamos alegando que os homens sofrem tanto quanto as mulheres as consequências das suas masculinidades vestidas. Porém, é urgente apontar que não é facultativo ser determinado tipo de homem e que, quando se resiste e se aposta noutro masculino, um preço é cobrado.

Um desses preços - que tem lá suas viabilidades de pagamento, ainda que espinhosas - diz respeito aos obstáculos que muitos homens encontram pelo caminho quando decidem ser professores (e, como um de nós, professor da Educação Infantil). 0 magistério, bem sabemos, apresenta-se historicamente entre os horizontes profissionais autorizados para as mulheres e, temos sempre que sublinhar, esse processo feminino de ocupação das salas de aulas se efetiva a partir de determinadas representações de gênero que costumam definir os lugares sociais previstos para homens e mulheres, sendo tais operações integrantes de um processo histórico (LOURO, 2001). A 


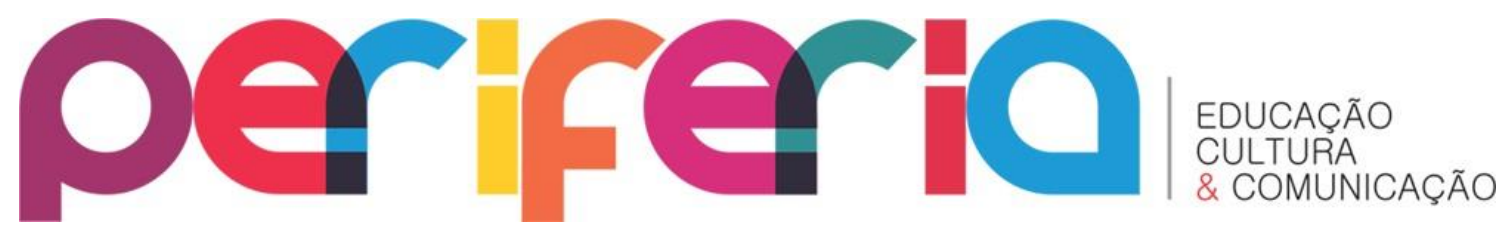

condução da mulher ao trabalho (mal) remunerado de professora - a tia ${ }^{4}$ - se dá em grande medida por uma espécie de aprisionamento histórico no mundo privado que, tal como um fardo, liga o feminino às atividades de cuidado, de criação, um tipo de vocação para formar seres humanos que, se homens, atuarão no mundo público, espaço ainda atravessado por privilégios masculinos (FARIA, 1989).

A divisão sexual do trabalho - e a distribuição do poder e do prestigio a ela associada - é (...) uma construção sócio cultural e não biológica. A diferenciação de gênero é (...) realizada mediante atividades específicas. Trata-se, de fato, de papéis sócio-sexuais, entendidos como práticas institucionalizadas, como cristalização de relações sociais (ROMANI, 1982, p. 70).

Ao sinalizarmos que o mundo público - a rua, o mercado, a praça encontra-se ligado a uma primazia do trânsito masculino - os homens circulam a qualquer hora, com qualquer roupa, em qualquer espaço e não correm o risco de serem estuprados, por exemplo - não podemos perder de vista que uma das consequências dos inúmeros movimentos que existem dentro e fora do Movimento Feminista foi a conquista do alargamento das possibilidades das mulheres de habitarem o espaço público, seja na ocupação de novos postos no mercado de trabalho, seja na ressignificação das antigas ocupações e, sobretudo, nas implicações que essas novidades trouxeram para os homens que se acostumaram a reinar solitários em territórios pretensamente seus (supostamente nossos). É imperativo discutir, acompanhando a recomendação de Sócrates Nolasco (1993)

a maneira opressiva pela qual tradicionalmente os homens são socializados. Os homens abrem mão da própria liberdade quando negam seus limites, história de vida, desejos e sonhos

\footnotetext{
${ }^{4}$ Nilda Alves contou, certa vez, em sala de aula, que sempre atribuiu um caráter pejorativo ao termo "tia" quando destinado às professoras. Contudo, ao assistir um filme (ou documentário, não lembro) entendeu que os praticantes da escola filmada expressavam por meio do "tia" certo aceite da professora naquele grupo social. Neste caso, ser "tia" estaria ligado ao aceite da comunidade escolar.
} 


\section{periferio}

para tentar reproduzir o padrão de comportamento definido a priori para eles (p.12).

Betty Friedan (1983), na mesma direção, ao pesquisar um grupo de homens, argumentou que esta dificuldade de lidar com as emoções e, sobretudo, com as fragilidades e incertezas, dificulta construir ações que pensem os desafios de uma masculinidade hegemônica, restando aos homens o isolamento em seus próprios questionamentos. Ela entende que os homens não ficaram imunes ao Movimento Feminista e que precisaram rever suas práticas diante das novas configurações exploradas pelas mulheres. Contudo, teriam efetivado essas pequenas mudanças por meio do que ela nomeia movimento silencioso dos homens, algo mais ligado às biografias do que ao movimento social. Os homens que ela entrevistou - americanos de classe média alta, é preciso frisar - reconstruíram suas vidas apostando em outras possibilidades de exercício da masculinidade, geralmente abandonando os antigos empregos e as velhas esposas, casando-se novamente com parceiras mais jovens, tendo filhos da idade dos seus netos e vivendo, nessa paternidade tardia, experiências negadas quando do nascimento dos primeiros filhos, já que as preocupações naquela ocasião giravam em torno do sustento da casa e não exatamente na construção de laços de afeto com a nova cria.

É mais difícil observar a modificação entre os homens porque eles têm mais dificuldade de falar sobre o que sentem que as mulheres. Certamente não discutem seus sentimentos com outros homens. É parte da mística masculina - a definição do homem pelo seu escore competindo contra outros homens - que deve sempre ficar na defensiva (FRIEDAN, 1983, p. 121).

A masculinidade é definida por Oliveira (2004) como um lugar simbólico que atua intensamente nos discursos e nas práticas possibilitando um processo de autoconstrução comprometido com o alcance de determinadas metas. Mito efetivo da Modernidade, a masculinidade hegemônica foi cerzida com as linhas do processo civilizatório, pois esgarçada pelas tantas transformações da estrutura social. A essa costura dos modos de ser masculinos dedicaram-se 


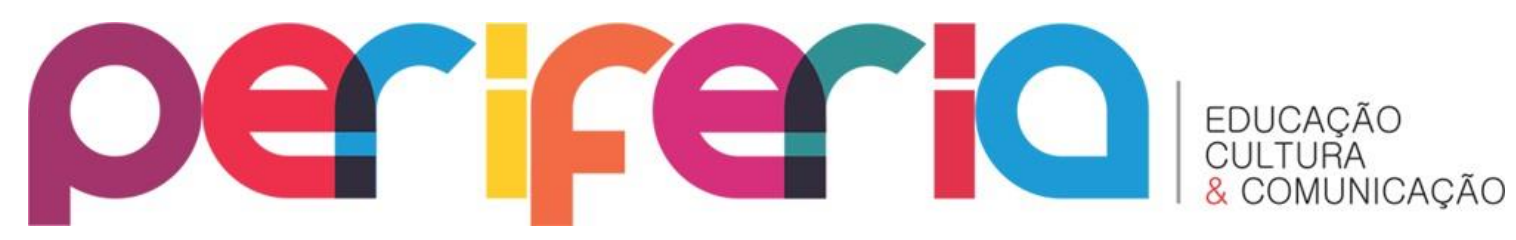

vários dos ideais burgueses, sempre tentando equilibrar as demandas de um novo modelo de homem que se fazia necessário - já que seria difícil manter intocadas as vestes do macho da Idade Média - com certos bordados de distinção que nos permitisse continuar diferenciando o homem da mulher, esses esboços que parecem não sair de moda. A justa medida dos modelos talhados nos corpos masculinos de qualquer idade seria dada pelo aval dos grupos que nos cercam, pela aceitação de nossos modos de estar no mundo ou pela percepção de que erramos a mão, passamos do ponto, enviadamos, desmasculinizamos o que jamais poderia ser desmasculinizado.

Recorrendo a um estudo de Philip R.D. Corrigan denominado "The making on what grammar school did with to and for my body", datado de 1991, Louro (1999) irá apontar para o processo de escolarização do corpo e das ações da criança. 0 autor descreve uma experiência pessoal vivida em uma escola particular inglesa - Aske - quando de sua entrada no ginásio. Recorda que no primeiro dia de aula os alunos mais velhos eram incentivados a bater nos novatos, para que estes reconhecessem desde o início que estavam entrando em um território comandado por outros homens e que para ter direito ao seu próprio espaço, era necessário demonstrar força, coragem e disciplina. No ano seguinte seria a vez deles comprovarem os seus poderes e assim sucessivamente, até que muitas gerações aprendessem o valor da masculinidade através daquela instituição de ensino. Em Aske, no decorrer do ano letivo, o incentivo à assimilação de uma masculinidade hegemônica se fazia presente através dos esportes, das competições e da legitimação da violência como meio de atingir um direito inconteste - o direito de dominar o mundo.

(...) ser homem significa amputar seu corpo e seu coração sem poder chorar. Ser homem significa ser capaz de cometer violência contra seus próprios sentimentos, contra suas próprias emoções, contra seu próprio corpo - ser capaz de esquecer que se tem um coração e um corpo (COURNEAU, 1995). 


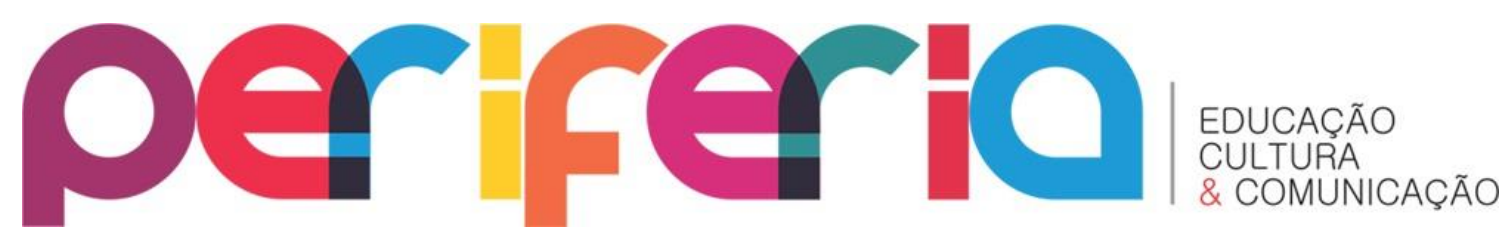

Encontramos embutida na definição do que vem a ser "homem" a ideia de oposição e negação àquilo que seria o seu oposto: a mulher. Repetimos nas falas cotidianas supostas provas desta "incontestável" diferença: mulheres são mais emotivas; homens são objetivos; o homem trai porque a carne é fraca; mulheres dirigem mal... São tantas as fabulações que recorrem à natureza para justificar a construção de determinados modos de existir que passamos, sem muito questionar, a reproduzir esses discursos, produzindo mundos a partir deles.

Joana (quatro anos) - Só princesa usa rosa! Você é menino. Só pode brincar de verde do Ben $10^{5}$ ! (conversando com o amigo que estava com uma massinha rosa)

Professor - Mas quem não é princesa não pode usar rosa por quê?

Joana - Porque menino não é menina.

O diálogo acima, ilustração de tantas conversas que já tivemos na vida, mostra o quanto a construção das masculinidades dialoga com a negação e a inferiorização do feminino. Corneau (1995, p. 47) sintetiza este movimento da seguinte forma: "Ser homem significa não ser mulher".

Se pensarmos a masculinidade hegemônica como um produto que demanda ser utilizado por todos que nasceram sob o sexo biológico classificado de masculino, não podemos esquecer que entre a produção e o consumo há todo um caminho de ressignificações, como aponta Certeau (2014). Por mais que existam programações prévias, ratificadas por uma série de tecnologias sociais, os sentidos produzidos pelos usuários são da ordem do imponderável. Adiante, quando trouxermos as narrativas das criançasestudantes observadas nesta pesquisa, veremos o quanto a atualização das masculinidades é uma prática cotidiana talhada nos mais sutis movimentos da vida comum. "É (...) necessário analisar a sua manipulação pelos praticantes que não a fabricam. Só então é que se pode apreciar a diferença ou a

\footnotetext{
${ }^{5}$ Ben 10 é um super-herói de desenho animado. Trata-se de um garoto que adquiriu um dispositivo alienígena na forma de um relógio de pulso. Este objeto permite que o menino se transforme em seres alienígenas, cabendo a ele (uma criança) a segurança do seu planeta.
} 


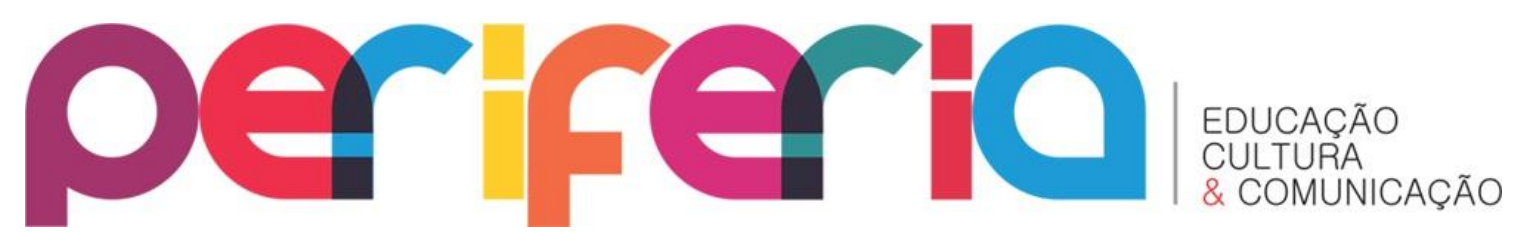

semelhança entre a produção da imagem e a produção secundária que se esconde nos processos de sua utilização". (CERTEAU, 2014, p.39).

No caso das crianças, cujo processo de socialização ainda caminha os primeiros passos, as possibilidades de invenção (ou de operações de usuário) costumam gozar de maior liberdade. De acordo com Kramer (2009), a criança é um sujeito que pratica invenções e que produz outras lógicas, ampliando as formas de conceber, por exemplo, as questões de gênero. É isto que ouvimos de João, numa interação de sala de aula:

\footnotetext{
João - Olha! O meu vestido do Ben 10! (enquanto se enrolava numa toalha e falava com o professor).

Professor - Que legal, João! Você gosta de vestido?

João - É... O Ben 10 podia usar vestido.
}

Dificilmente teríamos este diálogo na universidade. A fabulação do mundo através dos poderes e autorizações morais dos super-heróis é algo que nem sempre trazemos para a vida adulta. A criança, ainda de acordo com Kramer (1999), possui um olhar crítico que "vira pelo avesso a ordem das coisas, que subverte o sentido da história” (p.2). É no costurar das relações com a imaginação, com a brincadeira e com a fantasia que as crianças quebram as barreiras e testam outros mundos dentro de um mundo nosso.

Percebam que, a todo momento, indicamos que as masculinidades - já podemos usar no plural - são produzidas na prática cotidiana, pois não natural. Por isso, dizemos que são masculinidades encenadas - ou praticadas, para ficarmos no âmbito do discurso certeauniano.

Embora sejam compostas com os vocabulários de línguas recebidas e continuem submetidas a sintaxes prescritas, elas desenham as astúcias de interesses outros e de desejos que não são nem determinados nem captados pelos sistemas onde se desenvolvem. (CERTEAU, 2014, p. 44-45).

Aos não desejáveis processos de desmasculinização respondem prontamente toda uma engenharia social fabricada para vigiar 


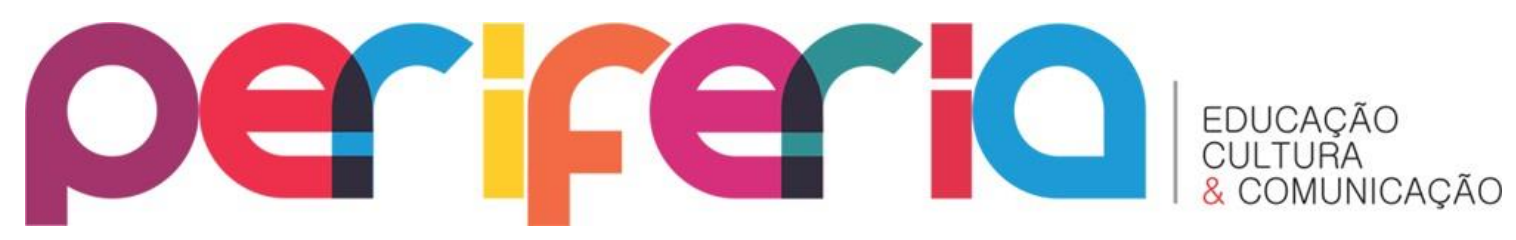

comportamentos e estimular subjetivações. "Perder a feminilidade ou a masculinidade é uma ameaça constante e as regras para que tal não ocorra devem ser acatadas desde a infância, nos tipos de brincadeira, nos 'modos', no 'próprio' de meninas e de meninos" (ROMANI, 1982, p. 60).

Para serem acatadas, todavia, as regras precisam ser ensinadas. Participam deste ensinamento variados atores e instituições, de modo a nos fazer esquecer, de repente, que agimos por aprendizado e não por impulso. Durkheim (1955) costumava dizer que a escola passou a ocupar na Modernidade o lugar privilegiado da aprendizagem moral de cada tempo histórico. O professor, segundo ele, captaria na sociedade as demandas de cada época e conduziria o seu trabalho de modo a fabricar nas crianças tábulas rasas, na visão do autor - determinadas disposições morais que garantiriam a coesão social. A educação moral da juventude, nessa perspectiva, constituía-se numa saída para evitar a anomia (ausência de regras), já que as instituições de origem - família e religião, principalmente encontravam-se enfraquecidas devido às mudanças impostas pela Revolução Francesa e pelo avanço do capitalismo. Ao lado da escola - responsável por educar moralmente as crianças - atuaria também a divisão do trabalho social responsável por reconstituir e manter os laços de solidariedade entre os adultos. Esta divisão seria

capaz de suceder a família nas funções econômicas e morais que ela se torna cada vez mais incapaz de preencher, (...) será preciso pouco a pouco vincular os grupos de homens às suas vidas profissionais, constituir fortemente os grupos desse gênero, será preciso que o dever profissional assuma, dentro dos corações, o mesmo papel que o dever doméstico desempenhou até agora (DURKHEIM, 1921, p. 13).

O que Durkheim, intelectual de seu tempo, não percebeu é que a formação não acontece apenas nos espaços institucionalizados para tal fim. "A formação do professor não se dá exclusivamente no âmbito da formação acadêmica" (ALVES, 2015, p. 65), por exemplo. Somos constituídos por uma 


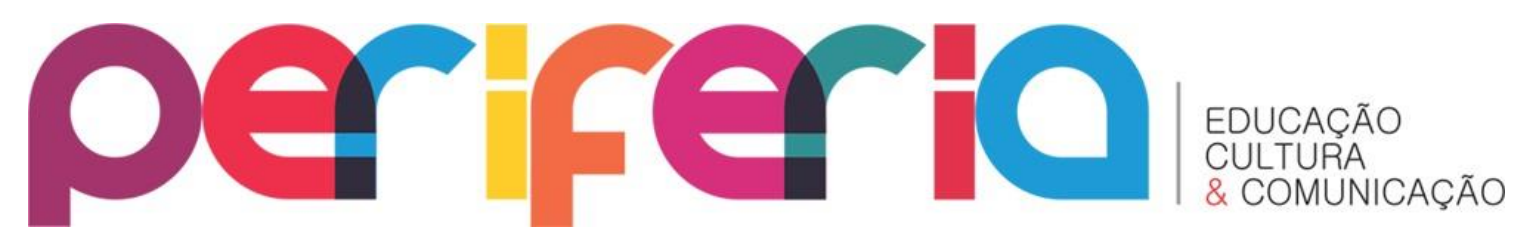

infinidade de redes e referências, sempre moduláveis, prontas para novas e imprevisíveis configurações.

O imprevisível é, pois, um campo aberto à invenção. Por isso, Kastrup (2005) nos recomenda alimentar a atitude de uma criança que, na fase das perguntas, nunca se contenta com a primeira resposta obtida. Uma pergunta leva a outra e aprenderensinar é como um desejo de seguir. Nesses caminhos, enquanto lapidamos a prática do perguntar, podemos experimentar a desestabilização das formas tradicionais do pensar. Esse é o momento da invenção do problema, um estágio de perturbação que ela classifica - a partir de Deleuze - como breakdown. Nenhuma aprendizagem está imune à perturbação e a única estabilidade é a invenção.

O conceito de "perturbação" ou de "breakdown" responde pelo momento da invenção de problemas, que é uma rachadura, um abalo, uma bifurcação no fluxo recognitivo habitual. O conceito de "breakdown" é essencial na argumentação de que não existe mundo prévio, nem sujeito preexistente. 0 si e o mundo são co-engendrados pela ação, de modo recíproco e indissociável. Encontram-se, por sua vez, mergulhados num processo de transformação permanente. Pois ainda que sejam configurados como formas, estas restam sujeitas a novas perturbações, que forçam sua reinvenção. (KASTRUP, 2005, p. 1276).

É exatamente nesse ponto que gostaríamos de chegar para, a partir dele, inscrever os processos de formação como processos de subjetivação. Formar é subjetivar! Formação não é formatação, mas sim um processo de invenção de si e do mundo (KASTRUP, 2005), isto é, um processo de produção de subjetividade e de singularização. De que forma os super-heróis de desenhos animados interferem na invenção do masculino? Em que medida as séries adultas modificam ou ratificam tais invenções das masculinidades?

\section{AUDIOVISUALIDADES E PROCESSOS FORMATIVOS}




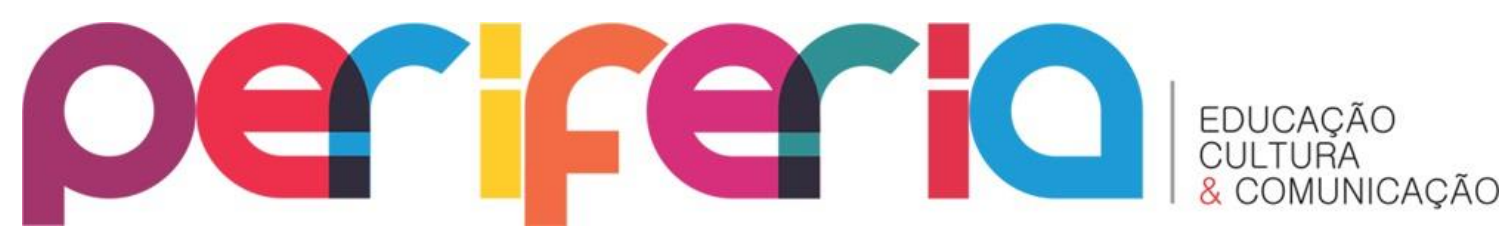

Rincón (2002), pensando o audiovisual como uma estratégia fundamental na relação dos sujeitos com o mundo e com a vida na sociedade contemporânea, nos indica a noção de sensibilidade como importante chave de leitura. As sensibilidades, segundo ele, operam como estratégias para imaginar a diferença em meio ao fluxo caótico e barroso de imagens. A imagem funciona como uma maneira de pensar e narrar a existência. Nesse contexto, o audiovisual se configura como uma possibilidade de fabular o mundo através do cinema, da televisão, do vídeo, da internet. Uma fabulação que constrói maneiras de ser, de agir, de se integrar à sociedade com lógicas análogas às das práticas cotidianas. Entendemos, pois, o audiovisual como uma forma de pensamento que se articula - ou pode ser articulada - com maneiras outras de pensar o mundo - entre elas a filosofia e a teorias científicas, por exemplo. Parece-nos possível discutir a partir do que vemos/ouvimos/sentimos nas telas (múltiplas na contemporaneidade) a produção social de variadas sensibilidades (des?) ligadas ao gênero e às sexualidades - tema que nos é caro e fundamental no tempo presente. Também com os audiovisuais, acreditamos, se tecem em redes as narrativas do presente.

A intrusão das narrativas audiovisuais, especialmente as televisivas e cinematográficas, em nossas vidas cotidianas não é recente. Também não é novidade o modo pelo qual elas desorganizam e reorganizam as práticas culturais, se constituindo, simultaneamente, em um desafio e em novas possibilidades para a educação. De acordo com Martín-Barbero (2000), em toda a América Latina as maiorias se incorporaram à modernidade "não sob o domínio do livro, mas a partir dos discursos e das narrativas, dos saberes e das linguagens da indústria e da experiência audiovisual” (p.83). Não tardou para que a escola encontrasse nos filmes, documentários, desenhos animados e afins um meio para alcançar, através do sensível, a atenção do aluno para, a partir disso, desenvolver determinados temas.

Tal encontro, já amplamente experimentado no cotidiano escolar (com maior ou menor sucesso), costuma acontecer em meio às controvérsias das práticas 


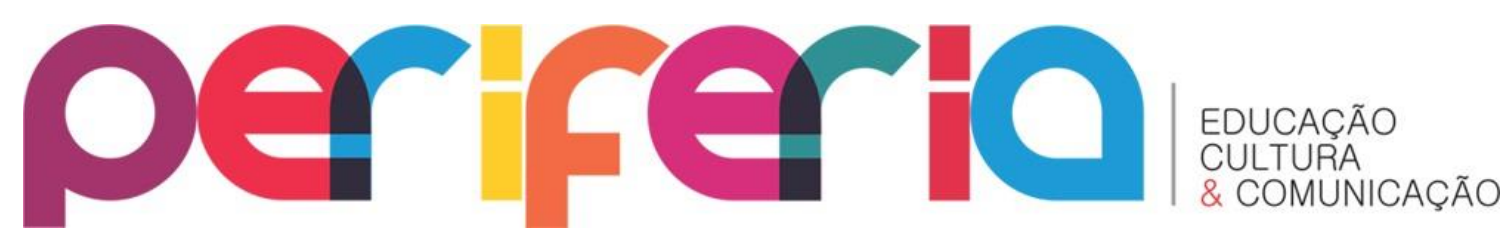

didáticas que, buscando inovar a experiência educacional, repetem a monologia do professor-intérprete que facilita a 'aprendizagem' do alunoouvinte. Após a exibição do audiovisual, nesses casos, o professor costuma didatizar o conteúdo, construindo 'pontes' por onde, muitas vezes, só ele caminha, procurando no filme um suposto ponto de apoio que justificaria a exibição com fins educativos. Quem escolhe a obra a ser exibida? Que critérios norteiam essa escolha? Que sentidos são planejados? Que desdobramentos são previstos e como o professor lida com o imprevisível, com a reação da turma? Nossa memória discente está repleta de lembranças daquele filme exibido na sala quando o professor precisava faltar (ou quando ele não estava a fim de 'dar aula'). Para escapar dessa armadilha, tentamos conversar com o consumo dos audiovisuais que já fazem parte do cotidiano dos estudantes, buscando ressoar temas já contidos em suas experimentações diárias diante das telas ${ }^{6}$.

Se com as crianças atentamos para a participação dos desenhos animados na construção das masculinidades, com os estudantes universitários elegemos como disparador do tema o seriado televisivo The Walking Dead ${ }^{7}$. Nosso cenário nesta empreitada foi a sala de aula de uma graduação tecnológica formada exclusivamente por homens. A partir de episódios editados pelo professor, selecionados considerando a maior presença de conflitos ligados aos ideais de uma masculinidade hegemônica e de uma

\footnotetext{
6 Insistimos na utilização da palavra "telas" para frisar a multiplicidade de dispositivos voltados à exibição dos produtos audiovisuais. Não mais a exclusividade do cinema ou da televisão. Ao lado destas tecnologias aparecem celulares, tabletes, computadores portáteis e afins. A partir desta variedade crescem também não apenas as formas de consumo, mas os modos de produção. As teorias da recepção encontram-se, assim, na iminência de ampliar as leituras para abarcar o expectador-produtor-interagente dos audiovisuais - ou das audiovisualidades, como temos chamado concordando com Suzana Killp. De acordo com Killp (2012), as audiovisualidades correspondem ao modo como vem sendo chamadas as produções engendradas no limiar do audiovisual, embaçando as fronteiras construídas pelos pesquisadores e realizadores entre códigos imagéticos, gêneros e produção-consumo.

7 Série de televisão dramática e pós-apocalíptica norte-americana, desenvolvida por Frank Darabont e baseada na série de quadrinhos de mesmo nome, desenvolvida por Robert Kirkman, Tony Moore e Charlie Adlard. A série é protagonizada por Andrew Lincoln, que interpreta Rick Grimes, um vice-xerife que acorda de um coma e descobre-se em um mundo pós-apocalíptico dominado por zumbis. Ele sai em busca de sua família e encontra muitos outros sobreviventes, ao longo do caminho.
} 


\section{periferio}

feminilidade em transição, reunimos narrativas que caminham entre o estranhamento e a identificação, possibilitando aos praticantespensantes daquele espaçotempo a (des) construção de alguns regimes de verdades, bem como a validação de outros. 0 debate das cenas começava nos encontros presenciais e se prolongava nos fóruns do Moodle $^{8}$ - espaçotempo complementar do curso em questão.

No mundo criado por The Walking Dead, as fronteiras entre masculino e feminino aparecem mais borradas que na teoria. Não são raras as personagens femininas que escapam do modelo donzela casta e indefesa. Michonne, por exemplo, é uma guerreira que sobrevive ao apocalipse zumbi sem o auxílio masculino, colocando-se, ao contrário, no lugar de protetora de alguns homens (Rick, Carl, Hershel). Com sua espada de samurai, ela corta cabeças impiedosamente, para espanto dos 'machos' do grupo. Sua postura ativa e segura a põe na mira do Governador e de Merle Dixon, representantes de um modelo de masculinidade hegemônica, que se esforçam para colocar aquela mulher 'perigosa' (e negra) em seu devido lugar. Essa tentativa de realocação parece não se limitar aos personagens. Sobre Michonne, um aluno escreveu no Moodle: "É muito improvável uma mulher assim, fria, na vida real. Ela não chora por nada, ela não tem medo de nada. E nem bonita ela é. Se fosse (bonita) teria condições de impor aquela marra toda".

Outra personagem que parece fugir do estereótipo de fragilidade atribuído à mulher é Andrea. Contudo, antes de se mostrar destemida e aguerrida, ela passa alguns episódios à sombra da proteção masculina. É protegida por Dale, depois por Shane, sofre com a morte da irmã Amy, até que precisa, por circunstâncias da nova vida, pegar em armas para sobreviver. Em dado momento, já transformada em guerreira, ousa tomar a iniciativa de um intercurso sexual com Shane. Sobre isso, um aluno escreveu: "Na verdade, Andrea sempre foi safada. Nunca me enganei com ela. Desde que foi para o

80 Moodle é o ambiente virtual de aprendizagem adotado pela faculdade. Todas as aulas precisam acontecer nesta plataforma. Nela, os professores hospedam os slides, vídeos, textos e atividades da aula. Isso significa que uma parte considerável do curso fica registrada no referido sistema. Parte das falas deste artigo foi retirada de lá. 


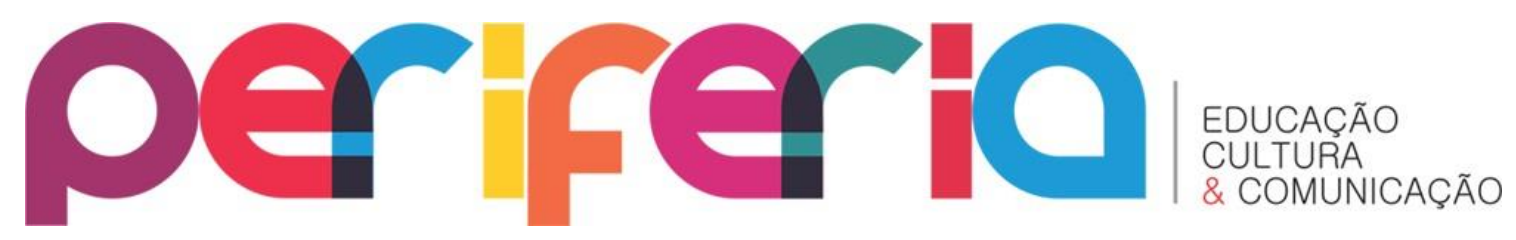

trailer do Dale com a irmã, ela se insinuava em troca de abrigo, comida e proteção. Por isso não me espanta ela ter traído o grupo pra ficar com o Governador. É o tipo de mulher que usa o sexo pra se dar bem".

A rejeição ao feminino transgressor foi uma tônica bastante presente nas narrativas desses alunos. Adjetivos como 'traiçoeira', 'vagabunda', 'perigosa', 'infiel' apareciam com frequência em suas análises dos episódios, sobretudo quando o tema girava em torno do triângulo amoroso vivido por Rick, Lori e Shane. Rick é o protagonista da série. É um vice-xerife que entra em coma depois de uma troca de tiros e acorda no hospital após o apocalipse. Lori é sua esposa, mãe de seu único filho, Carl. Shane era o parceiro de Rick quando ele levou o tiro e seu melhor amigo. Quando acontece a invasão zumbi, Shane inventa pra Lori que Rick está morto, convencendo-a a fugir com ele. Juntos, eles chegam a um acampamento com outros sobreviventes e Shane passa a ocupar o posto de liderança. Acontece que Rick não está morto e, tempos depois, também chega a esse acampamento e percebe que a esposa e o melhor amigo tornaram-se amantes. Essa tensão permanece no ar por muitos episódios e Lori descarta qualquer continuidade de envolvimento com Shane (envolveu-se com ele acreditando que era viúva). Shane, todavia, não desiste de Lori, mas também não admite pra Rick que ficou com sua mulher. Tudo se agrava quando Lori descobre-se grávida e a dúvida sobre a paternidade da criança é instaurada. Shane e Rick já são inimigos declarados nesse ponto da história, disputando também o posto de líder do grupo. Os examigos competem pela liderança, por Lori, pelo amor do pequeno Carl e pela sobrevivência. "Os meninos são educados para desenvolverem seus pontos de vista competitivamente, e, neste sentido, pouco articulados com o ponto de vista do outro, bem como distantes das necessidades que brotam de seus corações." (NOLASCO, 1993, p. 43). Shane tenta matar Rick, mas Rick se defende e mata Shane. Sobre esse desfecho trágico, escreveu um aluno: "Nessa história, nem Rick, nem Shane são culpados. A culpa é da Lori que não guardou o luto do marido e que, depois, não respeitou a honra do Shane, que 


\section{periferio}

a salvou. Se não fosse pelo Shane, ela e o Carl estariam mortos. Ainda bem que ela morre no parto".

Se as personagens femininas de TWD contam com essa recepção pouco amistosa dos alunos, os homens da série são tidos como heróis, inclusive aqueles apresentados como vilões. Um claro exemplo dessa disponibilidade para compreender atitudes socialmente recriminadas é o sucesso que 0 personagem Merle Dixon faz neste grupo. Tipo grosseiro, marginal e nada confiável, Merle foi chamado de "vida louca" pela turma. Em um dos episódios iniciais da série, ele coloca a vida de seu grupo em risco, dando tiros e atraindo os zumbis para a loja de departamento em que se encontravam abrigados (os zumbis são atraídos pelo barulho e o grupo de sobreviventes havia combinado agir em silêncio). Merle, repreendido pelos demais, é agressivo e incontrolável, impondo sua autoridade através da mira do revólver. Rick, recém-chegado ao grupo, consegue desarmar Merle e o algema numa das estruturas da cobertura do prédio em que estavam. Obtém, nesse momento, a aceitação do coletivo e inicia seu caminho de liderança. É sintomático que nessa ocasião (e em boa parte dos episódios que seguem) Rick se encontra uniformizado, parecendo ignorar que aquela indumentária faz parte do passado e que no novo mundo não há polícia. Há apenas mortos-vivos e sobreviventes caminhantes. Por que Rick está fardado? Por que Merle é tão admirado?

Começando pela última pergunta, a análise de um aluno: "Merle é o que ele poderia ser. Ele usa a violência porque é a única arma que ele tem. Todo mundo no grupo tem alguém que proteja, menos ele. Andrea tem a Amy, as duas tem o Dale; a Carol tem a Sophia e o Ed; todos são amigos do TDog e da Jacqui; o Rick tem a Lori e o Carl; até o Shane tem a Lori. Pro Merle só sobra o Daryl que é irmão, mas que não demonstra essa coisa de carinho, porque é casca grossa também. 0 jeitão do Merle não é por maldade. É sobrevivência mesmo". Essa naturalização da posição de constante combate do masculino é problematizada por Nolasco (1993): “Os padrões tradicionais definidos pelo modelo patriarcal para o comportamento masculino dissimulam 


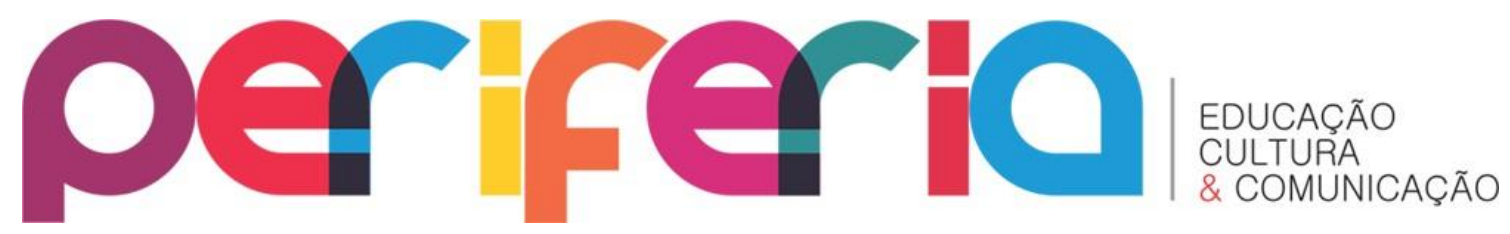

as possibilidades do encontro nas relações sociais, pois definem que em uma relação, a priori, alguém ataca e alguém defende, alguém ganha e alguém perde". (p. 43). Ou ainda:

Um menino cresce ignorando as sensações que brotam do próprio corpo, distanciando-se da possibilidade de formar uma visão particular sobre ele mesmo. Assim, ele é conduzido pela sedução viril da família e da escola por sobre sucessivos estereótipos machistas. Desta forma, eles são mantidos alheios aos afetos que os mobilizam e, portanto, embotam a sensibilidade que thes é característica. Um menino é educado nas precariedades de um cárcere, para quando crescer se tornar seu próprio carcereiro (NOLASCO, 1993, p. 47).

Merle parece ser perdoado pela ausência de opções na vida. Rick, seu algoz no momento em que o algema no alto do prédio, também não é culpabilizado pela turma: "Rick fez o que era certo fazer. Ele é um policial, precisa respeitar a lei”. Mas que lei? Não havia mais lei naquele mundo de TWD; não fazia sentido um policial vestido de policial, com direito a chapéu de xerife. Mas, para os homens, a identidade profissional sobrevive ao fim dos tempos, pois sem ela não sobreviveria o próprio homem.

(...) O trabalho define a primeira marca da masculinidade, na medida em que, no plano social, viabiliza a saída da própria família. (...) 0 trabalho e o desempenho sexual funcionam como as principais referências para a construção do modelo de comportamento dos homens. Desde cedo, os meninos crescem assimilando a ideia de que, com o trabalho, serão reconhecidos como homens. (...) Portanto, a crise na identidade dos homens se inicia com a crise no mundo do trabalho e da família e não com o feminismo (NOLASCO, 1993, pp. 50-55).

Consideramos sintomático que as ações das personagens de TWD sejam justificadas ou criticadas a partir dos estereótipos de gênero internalizados por cada um de nós. Em um universo de super-heróis aprendemos a validar certos tipos de comportamentos que, vez ou outra, serão acionados por nossa 


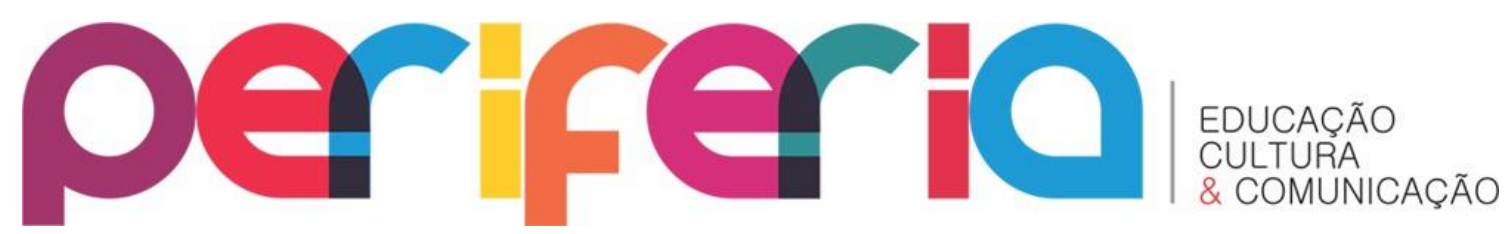

memória9 com o intuito de nos fazer escolher caminhos a seguir. Desde os conceitos e moralidades tecidos nos filmes infantis e aprofundados com menor sutileza nas produções audiovisuais adultas, vamos experimentando modos de existência que transitam entre a tela e a vida cotidiana. Friederichs (2012) acredita que as narrativas audiovisuais atuam na produção dos saberes, normas e experiências, influenciando modos de ser e estar no mundo ou de educar e significar os corpos. Os audiovisuais são, assim, formadores, pois os sujeitos, nas múltiplas relações estabelecidas, fabricam conhecimentos e significações (SOARES, 2013). Os filmes, séries, desenhos e novelas podem ser manuseados como problematizadores do que está dado/naturalizado na simulação das diferenças sexuais, por exemplo, cristalizando na percepção de meninos e meninas certos atributos supostamente exclusivos de um gênero ou do outro.

Vivian: " Eu sou homem de ferra!"

Carlos: "Não pode! O homem de ferro ${ }^{10}$ é menino."

Vivian: "Não! Eu sou homem de ferra, o homem de ferro que é menino"

Carlos: "Mas não existe homem de ferra"

Vivian: "É ... Tá bom, então vou ser o homem de ferro".

Carlos: "Mas não pode, você é menina, você vai ser a Cinderela;"

Vivian: Eu não! Vai ser você. Vou ser a homem de ferra sim

Ribes (2002) considera que a criança traz consigo uma habilidade para lidar com as - “eternamente novas” - tecnologias audiovisuais. Sendo assim, as pistas que pairam em torno dos modos de apropriação que as crianças fazem dos super-heróis são de uma potência que deixa passar o convívio com as incertezas. Tal destreza não somente a coloca numa posição de ruptura diante do adulto, como a transforma na tradutora, para o adulto, de múltiplas significações de uma criação que é sua (adulto), mas que muitas vezes soa

\footnotetext{
9 Memória, na perspectiva de Soares (2013), não é a reconstrução do passado, mas a fabulação de um passado nas contingências de um presente.

${ }^{10}$ Homem de Ferro é um personagem da Marvel. Sua identidade verdadeira é a do empresário Anthony Stark, que usa armaduras de alta tecnologia no combate ao crime.
} 


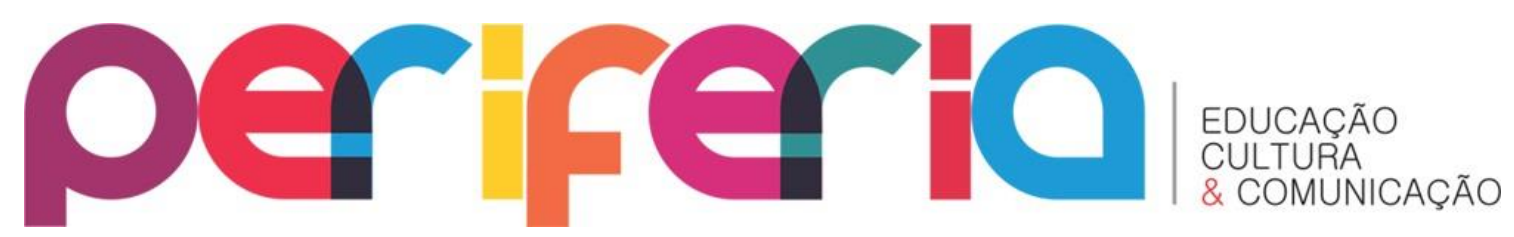

estranho para este adulto (idem, 2002). É nesta ótica que torna-se possível abordar a concepção do devir-criança, conforme nos fala Kohan (2004, p.64): "o devir-criança é o encontro entre um adulto e uma criança - o artigo indefinido não marca ausência de determinação, mas a singularidade de um encontro não particular nem universal." 0 autor argumenta que este encontro: "marca uma linha de fuga a transitar, aberta, intensa" (idem). Nietzsche (1995), por sua vez, diz que: “Neste mundo, só o jogo do artista e da criança tem um vir à existência e um perecer, um construir e um destruir sem qualquer imputação moral em inocência eternamente igual. $E$ assim brincam o artista e a criança [...]” (p. 49 e 50). Nietzsche atribui a potência da multiplicidade de impulsos e afetos às crianças, tendo elas a liberdade de criar a todo instante, modos de existência, fazendo e desfazendo, construindo e desconstruindo. Em que tela perdemos o costume de desfazer os gêneros como as crianças? Há quanto tempo não somos a homem de ferra? Em que armário deixamos dormindo nosso vestido do Ben 10? Por que queremos ser o xerife do Apocalipse zumbi e recusamos a proteção das Michonnes e Andreas? Entre cenas e senões, vestimos masculinidades nem sempre confortáveis e esquecemos (tantas vezes!) que a prática dispensa manual de instruções e que ser homem é da ordem da invenção.

\section{REFERÊNCIAS}

ALVES, Na. Nilda Alves: praticantepensante de cotidianos/ organização e introdução Alexandra Garcia, Inês Barbosa de Oliveira; textos selecionados de Nilda Alves. Belo Horizonte: Autêntica Editora, 2015.

CERTEAU, M. de. A invenção do cotidiano: 1. Artes de fazer. Petrópolis, RJ: Vozes, 2014.

CORNEAU, G. Paternidade e masculinidade. In:___ NOLASCO, S. A desconstrução do Masculino. Rio de janeiro: Rocco, 1995, pp. 43-52.

DURKHEIM, É. “La famille conjugale”. Revue Philosophique de la France et l'Étranger. Paris, $\mathrm{n}^{\circ} \mathrm{XCl}$, pp. 1-14, jan/ jun 1921. . Educação e Sociologia. São Paulo: Editora Melhoramentos, 1955. 


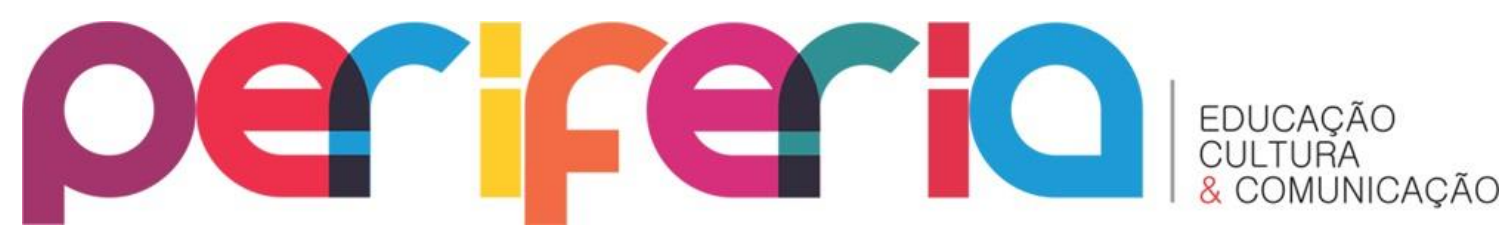

FARIA, L. A questão feminina no movimento das contradições da escola pública do Rio de Janeiro elou: quem é esta mulher que se torna professora? (Dissertação de mestrado). Rio de Janeiro: FGV/IESAE, 1989.

FRIEDAN, B. A Segunda Etapa. Rio de Janeiro: Francisco Alves, 1983.

FRIEDERICHS, M. Corpo, Gênero e Sexualidade em uma Cena do Cinema. IX Anped Sul -Seminário de Pesquisa em Educação da Região Sul, 2012, Caxias do Sul - RS. Corpo, Gênero e Sexualidade em uma Cena do Cinema, 2012.

KASTRUP, V. Políticas cognitivas na formação do professor e o problema do devir-mestre. Educação e Sociedade, Campinas, vol. 26, n 93, p. 1273-1288, set./dez., 2005.

KILPP, S. Dispersão-convergência: apontamentos para a pesquisa de audiovisualidades. In: MONTAÑO, S.; FISCHER, G;: KILPP, S. Impacto das novas mídias no estatuto da imagem. Porto Alegre: Sulina, 2012. P. 223 - 238.

KOHAN, W. O. A infância da educação: o conceito devir-criança. In: KOHAN, W. (Org.). Lugares da Infância. Rio de Janeiro: DP\&A, 2004.

KRAMER, S. Retratos de um desafio - Crianças e adultos na Educação Infantil. Rio de Janeiro: Ática, 2009.

LOURO, G. L. "Pedagogias da Sexualidade". In: (Org.). O Corpo Educado: pedagogias da sexualidade. Belo Horizonte: Autêntica, 1999, pp. 7 34.

. "Mulheres na sala de aula". In: PRIORI, M. D. (Org.). História das mulheres no Brasil. São Paulo: Contexto, 2001.

MARTIN-BARBERO, J. Novos regimes de visualidade e descentramentos culturais. In: FILÉ, V. (Org). Batuques, fragmentações e fluxos: zapeando pela linguagem audiovisual no cotidiano escolar. Rio de Janeiro: D, P\& A, 2000. p. $83-112$.

NIETZSCHE, F. A filosofia na idade trágica dos gregos. Tradução de Maria Inês Madeira de Andrade. Rio de Janeiro: Elfos; Lisboa: Edições 70, 1995, p. 39-55.

NOLASCO, S. O Mito da Masculinidade. Rio de Janeiro: Rocco, 1993.

OLIVEIRA, P. P. A construção social da masculinidade. Belo Horizonte: Editora UFMG; Rio de Janeiro: IUPERJ, 2004. 


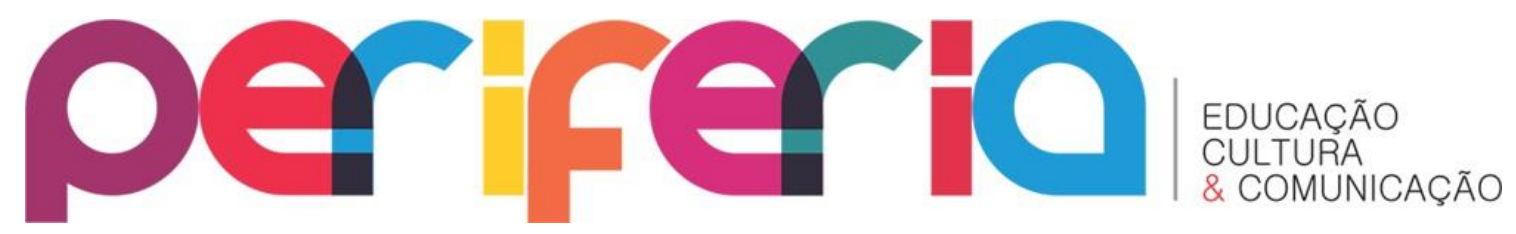

RIBES, R. Infância, Televisão e Publicidade: Uma metodologia de pesquisa em construção. Cadernos de Pesquisa, São Paulo, n. 115, p. 235-264, março/ 2002.

RINCÓN, O. Televisión, video y subjetividad. Bogotá: Grupo Editorial Norma, 2002.

ROMANI, J. P. de. "Mulher: natureza e sociedade”. In: LUZ, M. T. (ORG). O lugar da mulher: estudos sobre a condição feminina na sociedade atual. Rio de Janeiro: Edições Graal, 1982, pp. 59-71.

SOARES, C. Pesquisas com os cotidianos: devir-filosofia e devir-arte na ciência. Educação \& Realidade. Porto Alegre, v. 38, n.3, p. 731-745, jul/set. 2013. 